\title{
Temporary corneal stem cell dysfunction after radiation therapy
}

\author{
Hiroshi Fujishima, Jun Shimazaki, Kazuo Tsubota
}

\begin{abstract}
Background-Radiation therapy can cause corneal and conjunctival abnormalities that sometimes require surgical treatment. Corneal stem cell dysfunction is described, which recovered after the cessation of radiation.

Methods-A 44-year-old man developed a corneal epithelial abnormality associated with conjunctival and corneal inflammation following radiation therapy for maxillary cancer. He experienced ocular pain and loss of vision followed by conjunctival epithelialisation of the upper and lower parts of the cornea.

Results-Examination of brush cytology samples showed goblet cells in the upper and lower parts of the cornea, which showed increased fluorescein permeability, and intraepithelial lymphocytes. Impression cytology showed goblet cells in the same part of the cornea. Specular microscopy revealed spindle type epithelial cells. Patient follow up included artificial tears and an antibiotic ophthalmic ointment. The corneal abnormalities resolved after 4 months with improved visual acuity without any surgical intervention, but the disappearance of the palisades of Vogt did not recover at 1 year after radiation.

Conclusion-Radiation therapy in this patient caused temporary stem cell dysfunction which resulted in conjunctivalisation in a part of the cornea. Although limbal stem cell function did not fully recover, this rare case suggested that medical options should be considered before surgery.
\end{abstract}

Department of Ophthalmology, Tokyo Dental College, Chiba, Japan

H Fujishima

J Shimazaki

K Tsubota

Department of Ophthalmology, Keio University School of Medicine, Tokyo, Japan H Fujishima

K Tsubota

Correspondence to:

Hiroshi Fujishima, MD,

Department of

Ophthalmology, Tokyo

Dental College, 5-11-13

Sugano, Ichikawa, Chiba,

Japan 272.

Accepted for publication 24 May 1996

Radiation induced corneal epitheliopathy is one of the serious complications of radiation therapy. ${ }^{1}$ Manifestations of radiation induced keratopathy include superficial keratitis, stromal clouding, cell infiltration, and oedema of the cornea, ${ }^{2}$ and in severe cases perforation of the cornea ${ }^{3}$ can occur. Degeneration of the corneal epithelium, probably due to an irreversible inhibition of corneal mitosis after radiation therapy, was reported in experimental models. ${ }^{45}$

Corneal stem cells are essential to maintain the epithelial organisation by undergoing continuous turnover throughout adult life. ${ }^{6} 7$ The number of cells are maintained via the proliferation of a distinct subpopulation of stem cells. ${ }^{8}$
When the stem cells are severely injured, the conjunctival epithelium extends across the corneal scleral limbus, creating a thin and irregular surface over the cornea. ${ }^{9}$ Transdifferentiation of the conjunctiva to phenotypically normal corneal epithelium has been observed in some animal models and patients. ${ }^{10}{ }^{11} \mathrm{Limbal}$ transplantation (corneal stem cell transplantation) should be considered ${ }^{12-14}$ when the stem cell deficiency is thought to be permanent. We describe here a patient with radiation induced corneal epitheliopathy which resolved spontaneously within 4 months. Clinical course and change in tear function and ocular surface condition are reported.

\section{Patient and methods}

A 44-year-old Japanese man with advanced maxillary cancer of the left parasinus was treated with radiation from May to June 1993. A total dose of 61 Gy over 44 days (maximum dosage $3 \mathrm{~Gy} /$ day) was administrated via a right angled pair of wedge filtered portals. Three days after completion of the radiation therapy he complained of blurred vision and ocular surface pain in the left eye.

The cornea and conjunctiva were evaluated using slit-lamp examination, including fluorescein and rose bengal staining. Schirmer's test, the cotton thread test, ${ }^{15}$ and the clearance test ${ }^{16}$ were performed to evaluate the tear dynamics. Central corneal sensation was measured with a Cochet and Bonnet aesthesiometer (Luneau Ophtalmologie, France). ${ }^{17}$ Conjunctival cells were also evaluated by the brush cytology method. ${ }^{18}$ Smears containing cellular material were spread on glass slides in the usual manner, and then stained and fixed with a May-Grunwald stain solution (eosinmethylene blue solution; Muto Pure Chemicals Ltd, Tokyo, Japan). Impression cytology

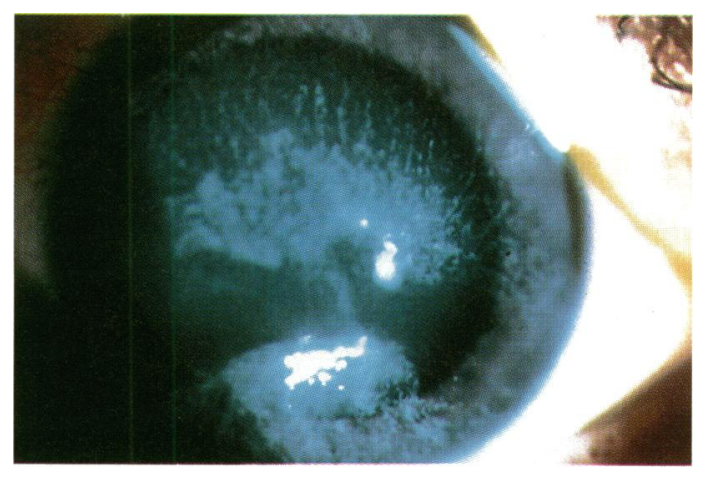

Figure 1 Corneal stem cell dysfunction 3 days after completion of radiation therapy. Upper and lower corneal epithelial cells showed damage, and epithelial opacity was apparent. The upper and lower parts of the cornea showed fluorescein staining. 
Table 1 Clinical findings

\begin{tabular}{lllllll}
\hline & First day & 4 roeeks & 8 weeks & 4 months & 6 months & 1 year \\
\hline Visual acuity (left eye) & $20 / 500$ & $20 / 250$ & $20 / 100$ & $20 / 100$ & $20 / 40$ & $20 / 25$ \\
Pain & +++ & ++ & + & - & - & - \\
Fluorescein stain & ++ & +++ & ++ & + & - & - \\
Rose bengal stain & +++ & +++ & ++ & + & \pm & \pm \\
Epithelial opacity & +++ & +++ & + & \pm & - & - \\
Corneal sensitivity $\left(\mathrm{g} / \mathrm{mm}^{2}\right)$ & $>17.68$ & & & 17.68 & & 12.84 \\
Goblet cell & + & & & - & - & - \\
Palisade of Vogt & - & & & & & - \\
Spindle type cell & + & & & & & \\
\hline
\end{tabular}

Figure 2 Examination of brush cytology samples. Goblet cells were detected in the upper and lower areas of the corneal surface.

was also performed using the method of Nelson et al (Schiff's Reagent; Muto Pure Chemicals Ltd, Tokyo, Japan). ${ }^{19}$ Specular microscopy (Kowa; Tokyo, Japan) was performed during the initial evaluation for blurred vision and again 12 months later.

\section{Results}

The previous examination, 6 months before initiation, showed no ophthalmic abnormalities of radiation therapy. At the initial examination, the patient's visual acuity was $20 / 40$ in his right eye and 20/500 in the left eye. A slit-lamp examination of the left eye showed corneal epithelial opacity, extending from the upper and lower limbus to the central cornea. Increased fluorescein permeability was detected in the area (Fig 1). Rose bengal staining was diffusely positive on the cornea. The palisades of Vogt

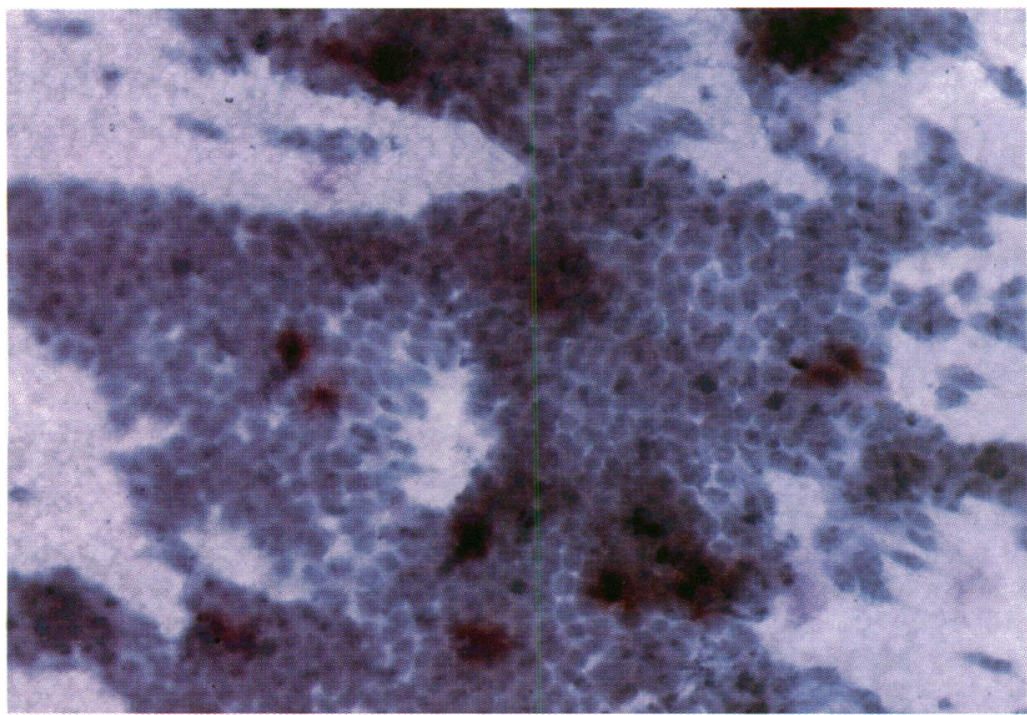

Figure 3 Periodic acid Schiff staining in impression cytology at the onset of complication. The mucin was stained red.
$(\mathrm{POV})^{20}$ were not observed. Corneal sensation showed $1.84 \mathrm{~g} / \mathrm{mm}^{2}$ in the right eye and greater than $17.68 \mathrm{~g} / \mathrm{mm}^{2}$ in the left. Schirmer's test, the clearance test, and the tear function index (TFI) were $9 \mathrm{~mm}, 8 \times$, and 72 (right eye) and $17 \mathrm{~mm}, 1 \times$, and 17 (left eye). Results of the cotton thread test were $32 \mathrm{~mm}$ (right eye) and $40 \mathrm{~mm}$ (left eye). The results indicated that tear flow was increased by the irritation but its drainage was poor in the left eye. Brush cytology samples in the upper and lower bulbar conjunctiva showed a few goblet cells including lymphocytes from inflammatory cells (Fig 2). Impression cytology also revealed goblet cells on the entire cornea (Fig 3). Specular microscopy in the central corneal epithelium revealed spindle-shaped and enlarged cells (Fig 4).

The patient was treated with preservativefree artificial tears (10 times a day) (Soft Santear eye drop; Santen Pharmaceutical Co, Osaka, Japan) and antibiotic ophthalmic ointment (twice a day) (Tarivid eye ointment; Santen Pharmaceutical Co, Osaka, Japan). After 4 weeks of follow up, epithelial opacity and vital stainings did not improve, and visual acuity remained at 20/250 (Fig 5). The patient still had ocular pain at this time.

After 8 weeks of follow up, epithelial opacity as well as vital staining gradually decreased. The visual acuity of the left eye improved to $20 / 100$, and ocular pain was markedly decreased. Four months after radiation therapy, scattered punctate epithelial staining was seen in the lower part of the cornea (Fig 6). Rose bengal staining was also decreased. Six months after the therapy, the patient no longer had ocular pain and his visual acuity recovered to $20 / 30$ in the right eye and $20 / 40$ in the left. Epithelial opacities and fluorescein staining had completely disappeared; however, slight rose bengal staining in the lower part of the cornea remained. The results of tear function tests performed 1 year after radiation therapy were as follows: Schirmer's test, clearance test, and TFI were $9 \mathrm{~mm}, 16 \times$, and 144 (right eye) and $29 \mathrm{~mm}, 1 \times$, and 29 (left eye), and cotton thread test was $35 \mathrm{~mm}$ (right eye) and $30 \mathrm{~mm}$ (left eye). Visual acuity recovered to $20 / 25$ in the left eye. Corneal sensation was $1.84 \mathrm{~g} / \mathrm{mm}^{2}$ (right eye) and it slightly recovered but still was $12.84 \mathrm{~g} / \mathrm{mm}^{2}$ (left eye). No goblet cells were detected by either brush cytology or impression cytology. Specular microscopy showed no spindle-shaped cells and cell configuration was normal (Fig 7). There was no complaint of ocular pain; however, the disappearance of the palisades of Vogt remained (Fig 8) (Table 1).

\section{Discussion}

$X$ ray treatment for parasinus carcinoma delivers a tumour lethal dose to the eyeball, which may lead to changes in the cornea and conjunctiva. Acute radiation reactions include temporary corneal punctate epithelial erosions. Delayed corneal complications may result directly from the effect of radiation or develop in association with the dry eye syndrome as a result of reduced or absent lacrimal secretions. ${ }^{1}$ A decrease in corneal sensitivity is a typical early sign of radiation keratopathy. Corneal 


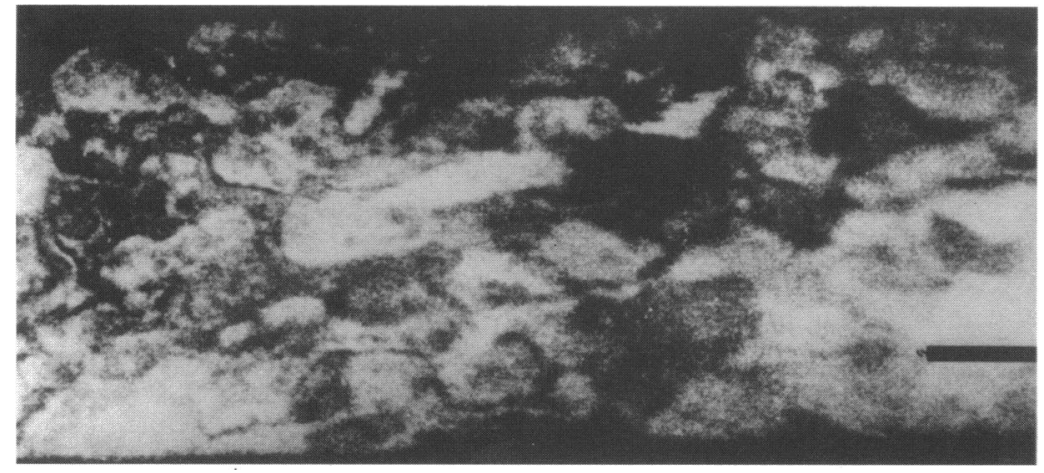

Figure 4 Specular microscopy performed at the onset of complications of radiation therapy. Spindle-type epithelial cells and large cells were seen.

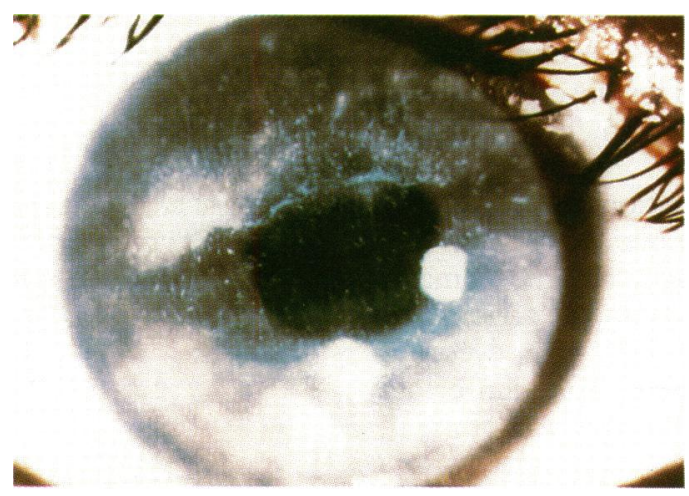

Figure 5 Corneal stem cell dysfunction 60 days after complication of radiation therapy. Slit-lamp examination showed a decrease in epithelial opacity. Fluorescein staining had largely disappeared.

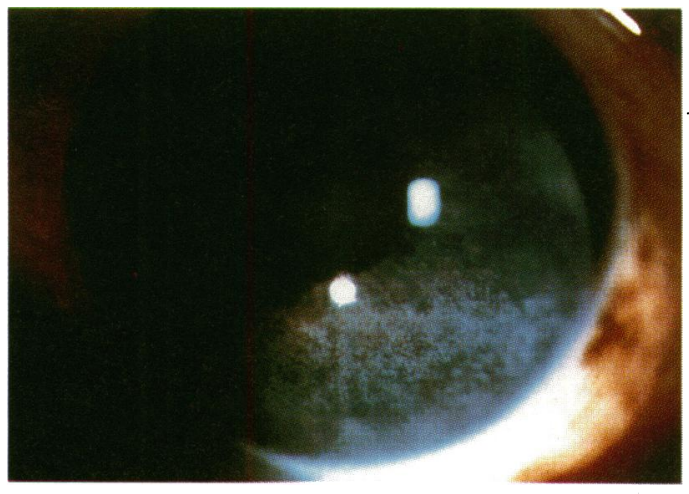

Figure 6 Slit-lamp examination 4 months after complication of radiation therapy. Only corneal epithelialitis was seen in lower part of the cornea.

keratopathy, characterised by epithelial and stromal oedema, ${ }^{1}$ has also been observed after radiation therapy. Electron microscopy has

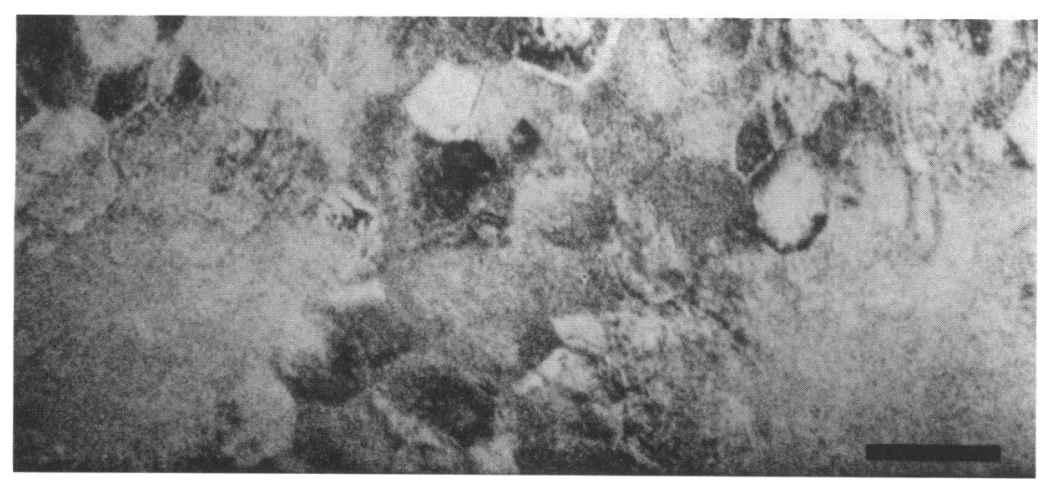

Figure 7 Specular microscopy performed 1 year after complication of radiation therapy. No specific changes were seen.

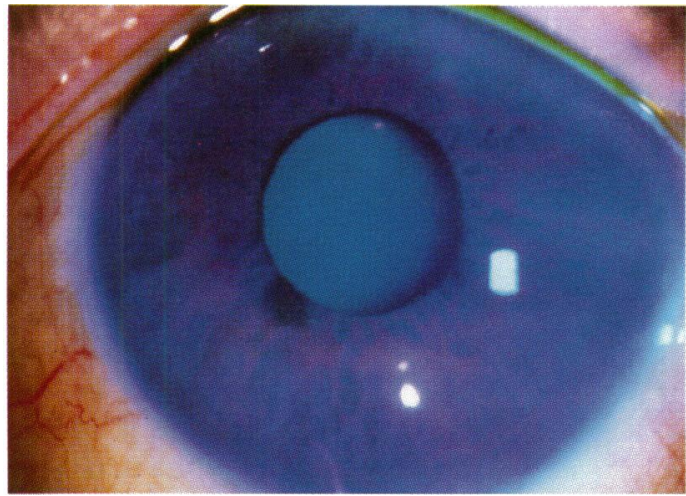

Figure 8 Slit-lamp examination 1 year after complication of radiation therapy. Cornea and conjunctiva were normal.

shown degeneration of the corneal epithelium probably due to irreversible inhibition of mitosis. $^{45}$

We have shown here a case of spontaneous recovery of radiation induced corneal epitheliopathy, with the presence of goblet cells whose permeability to fluorescein remarkably improved within 6 months. Since the corneal sensation, tear function, and disappearance of POV did not fully recover during the follow up, the improvement of the corneal epithelium was not due to the recovery of the sensation or tear function. Thus, we present this case as a 'temporary corneal stem cell dysfunction', which recovered gradually after the cessation of radiation.

Stem cells are a distinct subpopulation of basal cells located in various epithelial tissues. Corneal epithelial stem cells are believed to be located in the basal cell layer of the periphery of the cornea, the transition zone between the corneal and conjunctival epithelium, and the corneal limbus. ${ }^{21-23}$ Evaluation of $\mathrm{POV}^{20}{ }^{21}$ is a hallmark of the presence of stem cells. Under normal conditions stem cells, conjunctival epithelial cells, and vessels do not penetrate the cornea and corneal clarity is maintained. When the cornea is injured, active cellular renewal and differentiation can contribute to wound healing. ${ }^{24}$ The concept that limbal stem cell dysfunction includes conjunctivalisation was first proved by Tseng et al in serial experimental studies, and has been further confirmed by impression cytology in a recent report. ${ }^{10112425}$ Corneal stem cell dysfunction leads to corneal epithelial cell dysfunction. Conjunctival cell invasion leads to a decrease in visual acuity. In the present case, the presence of goblet cells in the cornea indicated that conjunctival cells had invaded the cornea and that epithelial cells had become dysfunctional. The recovery was thought to be due to the residual stem cells. As the temporal and nasal cornea were still clear and stem cells in these parts of the cornea still remained and functioned, this keratopathy could recover spontaneously. Other conditions, such as thermal burns, alkaline burns, chemical burns, contact lens injury, vernal conjunctivitis and radiation, may damage entire limbal stem cells so that the corneal epithelium cannot be repopulated. Radiation may also affect the mitotic rate of undifferentiated stem cells. The corneal abnormalities in the present case may have been related to temporary stem 
cell dysfunction, inhibition of epithelial mitosis, goblet cell hyperplasia, or a combination of these factors. ${ }^{25}$

After 8 weeks to 6 months of follow up, corneal epithelial cells covered the entire cornea. No spindle-type cells were present, suggesting that the rate of mitosis of corneal epithelial cells or stem cells may have recovered. A total daily dose of $3 \mathrm{~Gy}$, with a standard fractionation of 10 Gy per week in five fractions ( $2 \mathrm{~Gy}$ per treatment session), is considered safe for external beam radiation. For malignant tumours of the maxilla, a megavoltage dose of 60 Gy or more is performed. ${ }^{22}$ However, these doses were determined using a low energy 220 $\mathrm{kV}$ machine, which has still a higher incidence of complications than contemporary radiotherapeutic machines. ${ }^{26}$ The onset of corneal changes after radiation therapy varies from a few days to a year. ${ }^{32}$

Initial treatment of radiation related corneal abnormalities aims to remove any noxious elements that may cause further tissue damage. Specific treatment depends on the seriousness of the condition. Preservative-free eyedrops may be useful because tear dysfunction brings about these cases. Also, ointment and/or medical use contact lenses may be appropriate for a mild case. In a serious advanced case, limbal allo- or autograft transplantation must be considered. ${ }^{12-14}$ While the limbal stem cell function did not fully recover at 1 year after radiation, the present case showed clinical recovery of corneal and conjunctival abnormalities within several months, suggesting that medical options should be explored before surgery is considered.

The authors thank Ms Yukiko Yagi for performing the brush cytology, Ms Saori Nishijima for taking slit photographs, and Ke-Ping $\mathrm{Xu}, \mathrm{MD}$, for performing impression cytology.

1 Magfaul PA, Bedford MA. Ocular complications after therapeutic irradiation. $\mathrm{Br} f$ Ophthalmol 1970;54:237-47.

Scheie HG, Dennis RH, Ripple RC, Calkins LL, Buessele JA. The effect of low voltage roentgen rays on the norma and vascularized cornea of the rabbit. Am $\mathcal{f}$ Ophthalmol 1950;33:549-71.

3 Kadota Y, Okisaka S, Mizukawa A, Takahashi A. A case of corneal perforation and retinopathy followed by external radiotherapy for maxillary carcinoma. Folia Ophthalmol fpn 1988;39:2466-71.
4 Oinaka M. Experimental investigations of the late effects of ionizing radiation on the cornea. $f p n f$ Ophthalmol 1980;84:224-39.

5 Oinaka M. Experimental investigation of the late effects of ionizing radiation on the cornea. II. Folia Ophthalmol fpn 1981;32:1298-300.

6 Tseng S. Concept and application of limbal stem cells. Eye 1989;3:421-57.

7 Thoft RA, Friend J. The X, Y, Z hypothesis of corneal epithelial maintenance. Invest Ophthalmol Vis Sci 1983;24: 1422.

8 Hall PA, Watt FM. Stem cells: the generation and maintenance of cellular diversity. Development 1989;106: 619-33.

9 Dua HS, Forrester JV. The corneoscleral limbus in human corneal epithelial wound healing. Am $f$ Ophthalmol 1990;110:646-56.

10 Kruse FE, Chen JJY, Tsai RJF, Tseng SCG. Conjunctival transdifferentiation is due to the incomplete removal of
limbal basal epithelium. Invest Ophthalmol Vis Sci 1990;31: limbal bas 13 .

11 Puangricharern V, Tseng SCG. Cytologic evidence of corneal diseases with limbal stem cell deficiency. Ophthalmology 1995;102:1476-85.

12 Kenyon KR, Tseng SCG. Limbal autograft transplantation for ocular surface disorders. Ophthalmology 1989;96: 709-23

13 Pfister RR. Corneal stem cell disease: concepts, categorization, and treatment by auto- and homotransplantation of tion, and treatment by auto- and homotrans

14 Copeland RA, Char DH. Limbal autograft reconstruction after conjunctival squamous cell carcinoma. Am $千$ Ophthalmol 1990;110:412-5.

15 Sakamoto R, Bennet ES, Henry VA, Paragina S, Narumi T, Izumi Y, et al. The phenol red thread tear test: a cross-cultural study. Invest Ophthalmol Vis Sci 1993;34: $3510-4$

16 Xu K-P, Yagi Y, Toda I, Tsubota K. Tear function index: a new measure of dry eye. Arch Ophthalmol 1995;113: a new.

17 Cochet P, Bonnet R. L'esthesiometrie corneenne: Realisation et interet pratique. Bull Soc Ophtalmol Fr 1961;61: 541-50.

18 Tsubota K, Kajiwara K, Ugajin S, Hasegawa T. Conjunctival brush cytology. Acta Cytol 1990;34:233-5.

19 Nelson JD, Havener VR, Cameron JD. Cellulose acetate impressions of the ocular surface. Arch Ophthalmol 1983;101:1869-72.

20 Kinoshita S, Kiridoshi A, Ohji M, Ohashi Y, Manabe R. Disappearance of palisades of Vogt in ocular surface Disappearance of palisades of Vogt in ocular
disease. Fpn $\mathcal{F}$ Clin Ophthalmol 1986;40:363-6.

21 Davanger M, Evensen A. Role of the pericorneal papillary structure in renewal of corneal epithelium. Nature 1971; 229:560-1.

22 Takahashi H, Konno A. Ocular complication with therapeutic irradiation of malignant tumor in the maxilla. Folia Ophthalmol fpn 1983;34:320-4.

23 Zieske JD, Bukusoglu G, Yankauckas MA. Characterization of a potential marker of corneal epithelial stem cells. Invest Ophthalmol Vis Sci 1992;33:143-52.

24 Huang A, Tseng S. Corneal epithelial wound healing in the absence of limbal epithelium. Invest Ophthalmol Vis Sci 1991;32:96-105.

25 Chen JJY, Tseng SCG. Abnormal corneal epithelial wound healing in partial-thickness removal of limbal epithelium. Invest Ophthalmol Vis Sci 1991;32:2219-33.

26 Chako DC Considerations in the diagnosis of radiation injury. $¥ A M A 1981 ; 245: 1255-8$.

27 Khaw PT, Ward S, Grierson I, Rice NSC. Effect of $\beta$ radiation on proliferating human Tenon's capsule fibroblasts. $B r$ f Ophthalmol 1991;75:580-3. 